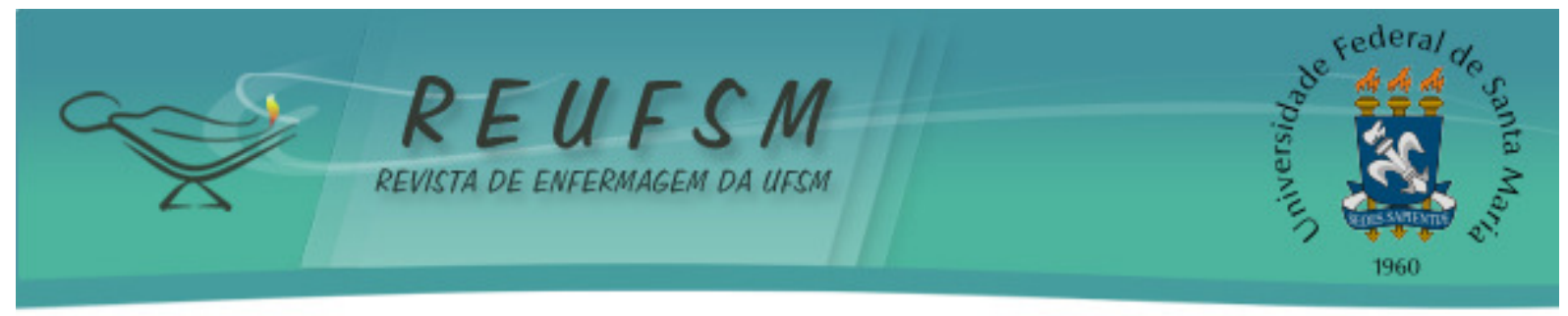

ARTIGO ORIGINAL

\title{
CUIDADOS DE ENFERMAGEM AOS USUÁRIOS COM DOENÇA DE PARKINSON NA ATENÇÃO BÁSICA DE SAÚDE
}

\section{NURSING CARE TO CLIENTS WITH PARKINSON'S DISEASE IN PRIMARY CARE HEALTH \\ CUIDADOS DE ENFERMERÍA PARA USUARIOS CON ENFERMEDAD DE PARKINSON EN LA ATENCIÓN PRIMARIA DE SALUD}

Barbara Juliana Konig Kuster ${ }^{1}$ Luiz Anildo Anacleto da Silva ${ }^{2}$ Marinês Tambara Leite ${ }^{3}$ Marta Cocco da Costa ${ }^{4}$

Doi: $10.5902 / 217976929074$

RESUMO: Objetivo: analisar as ações de cuidado realizadas por enfermeiros aos usuários com doença de Parkinson que acessam a atenção básica de saúde. Método: estudo qualitativo, descritivo, com análise temática. Os sujeitos da pesquisa foram nove enfermeiros atuantes na atenção básica em saúde. Resultados: Os resultados evidenciam que não há registro de usuários com essa patologia na área de abrangência do trabalho dos enfermeiros, podendo comprometer o cuidado de enfermagem aos indivíduos com doença de Parkinson. Considerações finais: A participação da família é relevante, devendo ser contemplada e integrada no planejamento dos cuidados de enfermagem aos indivíduos que possuem a doença de Parkinson.

Descritores: Doença de Parkinson; Atenção primária a saúde; Enfermagem em saúde pública; Enfermagem.

ABSTRACT: Aim: to analyze the actions performed by nurses care users with Parkinson's disease who access basic health care. Method: qualitative, exploratory and descriptive search with thematic analysis. The research subjects were nine nurses in Basic Healthcare Units. Results: The results show that there is no record of users with this disease in the area covered by the work of nurses, may compromise nursing care to individuals with Parkinson's disease. Final Considerations: family participation is important and should be addressed and integrated into the planning of nursing care to individuals who have Parkinson's disease.

Descriptors: Parkinson disease; Primary health care; Public health nursing; Nursing.

RESUMEN: Objetivo: analizar las acciones de cuidados realizadas por enfermeros a los usuarios con la enfermedad de Parkinson que tienen acceso a servicios básicos de salud. Método: investigación cualitativa, descriptivo con análisis temático. Los sujetos del estudio fueron nueve enfermeros que trabajan en la atención primaria de salud. Resultados: muestran que no existe un registro de los usuarios con esta enfermedad en la zona cubierta por el trabajo de los enfermeros, que pueden poner en riesgo los cuidados de enfermería a personas con la enfermedad de Parkinson. Consideraciones finales: participación de la familia es importante, debiendo ser contemplada e integrada en la planificación de los cuidados de enfermería a personas con enfermedad de Parkinson.

\footnotetext{
${ }^{1}$ Enfermeira egressa do Curso de Enfermagem da Universidade Federal de Santa Maria - Campus de Palmeira das Missões. Endereço. Email: Barbara_kuster@hotmail.com

${ }^{2}$ Enfermeiro. Doutor em Enfermagem. Docente do Curso de Enfermagem, da Universidade Federal de Santa Maria - Campus de Palmeira das Missões. E-mail: Luiz.anildo@yahoo.com.br

${ }^{3}$ Enfermeira. Doutora em Gerontologia Médica. Docente do Curso de Enfermagem, da Universidade Federal de Santa Maria - Campus de Palmeira das Missões. E-mail: tambaraleite@yahoo.com.br

${ }^{4}$ Enfermeira. Doutora em Enfermagem. Docente do Curso de Enfermagem, da Universidade Federal de Santa Maria - Campus de Palmeira das Missões. E-mail: Marta.c.c@ufsm.br
} 


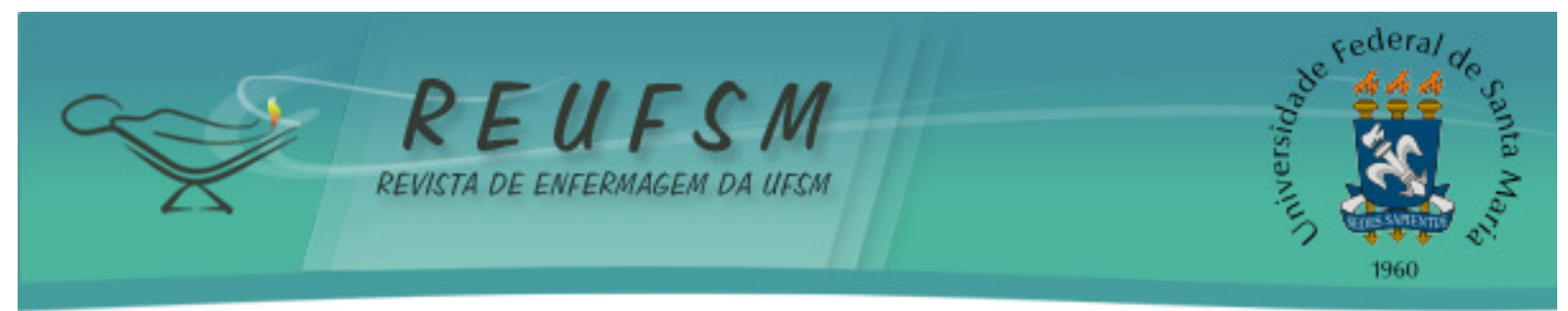

Descriptores: Enfermedad de parkinson; Atención primaria de salud; Enfermería en salud pública; Enfermería.

\section{INTRODUÇÃO}

A população mundial está envelhecendo e o contexto brasileiro acompanha esse processo. Esse perfil vem sofrendo modificações que deixam a pirâmide brasileira semelhante às de países desenvolvidos, em que há um número maior de pessoas acima dos 60 anos de idade. ${ }^{1}$ Mas, ao contrário dos países desenvolvidos, na realidade brasileira as possibilidades de um envelhecimento com qualidade de vida dos sujeitos estão aquém das necessidades. Outro fato agregado diz respeito à projeção de que haverá mais idosos do que crianças abaixo dos 15 anos por volta de $2050 .^{2}$

0 envelhecimento implica em uma série de demandas ligadas a enfermidades e agravos predominantes desta faixa etária. Assim, tem destaque as doenças degenerativas que são comuns na velhice, dentre elas, o Mal de Parkinson ou Doença de Parkinson (DP). Esta morbidade se sobressai devido à sua alta incidência, se constituindo na segunda doença neurodegenerativa mais comum entre pessoas com idade acima de 60 anos de idade, assim como as incapacidades produzidas nos seus portadores, tanto no campo motor quanto no cognitivo. ${ }^{3}$

Os primeiros registros da DP datam de 1817, quando o médico James Parkinson, em Londres, descreveu na monografia 'An Essay on the Shaking Palsy' um quadro por ele denominado como paralisia agitans, doença que posteriormente receberia seu nome. Havia pouco conhecimento, na época, sobre a enfermidade e, embora haja uma série de estudos recentes, suas causas e mecanismos ainda são controversos. ${ }^{4}$

Do ponto de vista epidemiológico, a Doença de Parkinson (DP) comumente é diagnosticada por volta da sexta década de vida ${ }^{1}$ sem prevalência de etnia ou gênero e de 150 e 200 pessoas são acometidas para cada 100 mil habitantes. Sua distribuição é homogênea e sua prevalência aumenta com o avançar da idade.$^{5-6}$ Atinge cerca de 10 milhões de pessoas no mundo e, no Brasil, há estimativas de que 300 mil pessoas são afetadas. ${ }^{7}$

Estudos mostram que sua ocorrência pode estar relacionada a fatores genéticos, quando sua manifestação se dá relativamente cedo, por volta da terceira ou quarta década de vida, e por fatores ambientais, como exposição a pesticidas e outras substâncias químicas. Tais informações podem sofrer algum nível de discordância, justificada pela insuficiência de dados neurológicos prévios ao diagnóstico médico. ${ }^{8}$

Bradicinesia, tremores e rigidez muscular são as três principais manifestações da DP. Pode, ainda, ocorrer diminuição da expressão facial, ausência de movimentos complementares a marcha e tremores grosseiros em repouso, principalmente de mandíbula e extremidades. Além das manifestações visíveis, a DP pode causar distúrbios do sono, problemas na articulação da fala, depressão e demências. Esta última, presente em estágios mais avançados da doença. ${ }^{1,3}$

As manifestações clínicas da DP só aparecem quando há perda de aproximadamente $80 \%$ dos neurônios dopaminérgicos e queda de quase $90 \%$ da dopamina no Sistema Nervoso Central. A terapia de reposição dos níveis de dopamina (levodopa) é a terapêutica de escolha para usuários com manifestações de DP, sendo a intervenção cirúrgica a última opção para usuários refratários ao tratamento medicamentoso. ${ }^{4}$

As limitações impostas ao usuário com DP desencadeiam impacto nos serviços de saúde, pois tendem a gerar diversas demandas à equipe que o trata e o acompanha e esta, por sua vez, precisa estar em constante aprimoramento para oferecer cuidado qualificado ao paciente e sua família. Tanto o tratamento medicamentoso quanto os procedimentos cirúrgicos são considerados terapias sintomáticas ou cirurgias paliativas, respectivamente, 


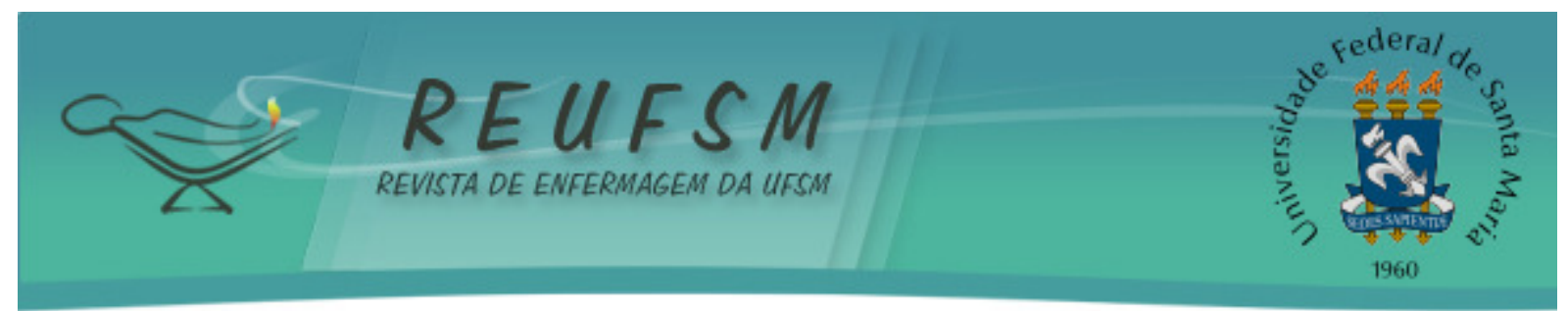

pois não impedem o avanço da doença, apenas retardam sua evolução natural, proporcionando uma melhor qualidade de vida ao portador de DP. ${ }^{4}$

No que tange à saúde da pessoa idosa, o Programa Nacional de Atenção ao Idoso (PNAI), assim como as outras políticas de saúde, preconiza diversas ações com foco na saúde dessa população ${ }^{2}$ com destaque para o eixo da promoção de um envelhecimento saudável e prevenção de doenças. Nesse contexto, a atenção básica de saúde se constitui em um importante espaço para o acesso da população aos serviços de saúde, pois permite a criação de vínculo entre comunidade e equipe de saúde das Estratégias de Saúde da Família ou das Unidades Básicas de Saúde, além de ofertar alternativas de acordo com as necessidades da população. ${ }^{2}$

Desse modo, compete à equipe de saúde, incluindo a enfermagem, disponibilizar apoio ao portador de DP sempre que necessário, ofertando as possibilidades de tratamento que auxiliem na melhora dos sintomas da doença e a manutenção da independência e da autonomia. As ações de enfermagem incluem a atenção ao paciente e a família, o que favorece para que esta acompanhe e esteja ao lado do paciente, sempre que ele precisar. 0 suporte familiar é fundamental igualmente nas fases mais avançadas, quando o paciente sofre perdas cognitivas acentuadas, em que há maior comprometimento motor, aumento do isolamento social e presença de depressão entre esses idosos. ${ }^{9}$

Preconiza-se a adoção de estratégias de melhoramento da qualidade de vida dos usuários, com vistas a atender às especificidades do paciente idoso, seja na manifestação de sintomas ou na complexidade de fatores que envolvem cada caso. Para tanto, busca-se facilitar o acesso do idoso e sua família aos serviços de saúde, desconstruindo a imagem do idoso passivo e diminuindo barreiras físicas e burocráticas que possam existir nestes locais. ${ }^{2}$

Outro viés a ser tratado, faz menção aos diferentes níveis de comprometimento que a DP imprime aos seus portadores. Um estudo indica a inexistência de uma relação direta entre o tempo de diagnóstico da DP e o nível de dependência de seus portadores, reafirmando a necessidade da avaliação individual para criar um plano de ações que vise suprir as necessidades e demandas de cada indivíduo.

Entende-se que a inserção do enfermeiro nas equipes da atenção básica de saúde e a complexidade de sua atuação, articulada com a equipe multidisciplinar, frente ao paciente e família com diagnóstico de DP justificam a opção pelo estudo. A questão de pesquisa busca responder: quais são os cuidados realizados por enfermeiros da atenção básica de saúde aos usuários com doença de Parkinson? Para tanto, o objetiva-se analisar as ações de cuidado realizadas por enfermeiros aos usuários com doença de Parkinson que acessam a atenção básica de saúde.

\section{MÉTODO}

0 estudo realizado é de natureza qualitativa, descritivo e exploratório ${ }^{10}$, desenvolvido nas Estratégias de Saúde da Família (ESF) em um município do Estado do Rio Grande do Sul.

0 município tem cerca de 35 mil habitantes e, destes, 1.168 são idosos acima de 65 anos. Assim, considerando estudos na área epidemiológica, projeta-se a existência de, aproximadamente, 38 casos de DP nesta população. ${ }^{11}$ O serviço de atenção básica se constitui de seis equipes de ESF, com tempo de implantação diversos. Duas delas existem há mais de cinco anos, três não completaram dois anos e uma implantada há um mês da época da coleta de dados; além destas, a rede é formada por uma unidade central que referencia a população descoberta pelas ESFs. A taxa de cobertura de ESF no local alcança um número aproximado de $60 \%$ e o município conta ainda com um hospital de médio porte. As demandas por especialidades de alta complexidade são referenciadas a outras cidades, muitas vezes distantes do município descrito. 


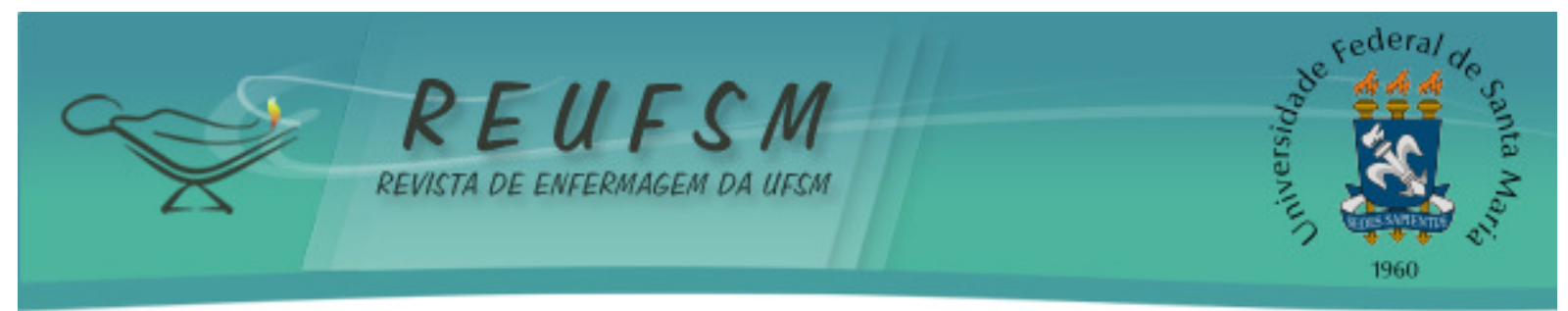

A definição dos sujeitos foi delimitada por uma amostra do tipo proposital ou intencional. ${ }^{12}$ Ser enfermeiro e atuar na ESF foram critérios de inclusão para participação. 0 número de entrevistados foi definido como saturado ${ }^{10}$, quando as informações coletadas passaram a se repetir. Participaram da pesquisa enfermeiros que, de livre e espontânea vontade, após conhecerem o projeto e assinarem o Termo de Consentimento Livre e Esclarecido, concordaram em fazer parte do estudo.

Os dados foram coletados entre julho e setembro de 2012. Foram sujeitos da pesquisa nove enfermeiros, sete do sexo feminino e dois do sexo masculino. 0 tempo médio de formação dos sujeitos foi de 4,7 anos, variando de seis meses a 16 anos, enquanto que o tempo médio de atuação profissional foi de 1,6 anos, oscilando de um mês a cinco anos. A coleta de dados ocorreu nas ESFs, com o auxílio de um instrumento que continha questões semiestruturadas. As entrevistas foram gravadas e, posteriormente, transcritas na íntegra. Para análise dos dados utilizou-se a analise temática. ${ }^{13}$

Neste estudo observou-se o que consta na Resolução196/96 do Ministério da Saúde. ${ }^{14} \mathrm{O}$ Projeto de pesquisa foi submetido e aprovado pelo Comitê de Ética em Pesquisa da Universidade Federal de Santa Maria, conforme parecer consubstanciado número 36529 de 12/06/2012. Os entrevistados estão identificados como E1, E2, E3 (...).

\section{RESULTADOS E DISCUSSÃO}

A partir do processo de categorização de dados advindos da pesquisa foi possível criar três temas, denominados 'Cuidados de enfermagem aos usuários com doença de Parkinson'; 'Cuidados direcionados aos familiares de usuários com doença de Parkinson'; e 'O usuário com doença Parkinson na atenção básica’ descritas e analisadas a seguir.

\section{Cuidados de enfermagem aos usuários com doença de Parkinson}

0 primeiro tema refere-se aos cuidados que deveriam ser implementados aos usuários com diagnóstico de DP. Embora esteja demonstrado na literatura que a doença de Parkinson acomete $3,3 \%$ da população idosa ${ }^{6}$, nas seis ESFs pesquisadas, evidenciou-se o não registro de usuários com essa patologia nas respectivas áreas de abrangência. Sobre o fato, os entrevistados assim se manifestaram:

A gente não tem nenhum paciente e eu acho que justamente por não ter nenhum paciente a gente nunca foi atrás, não tem [...] (E1)

Nós, enquanto estratégia hoje felizmente não tem nenhum paciente portador de doença de Parkinson. (E4)

Aqui dentro da área de abrangência, diagnosticado e em tratamento nós não temos nenhum paciente - pelo que a gente tenha conhecimento. (E5)

Os sujeitos da pesquisa, na ocasião, não souberam indicar a existência de pacientes com doença Parkinson pertencentes a suas áreas adscritas. O Ministério da Saúde ${ }^{2}$ orienta ações com vistas a ampliar o acesso deste público ao serviço, embora tais ações não tenham sido visualizadas na prática e nas falas dos entrevistados. Esse fenômeno pode ser explicado pela dificuldade de diagnóstico da DP, bem como por uma implementação frágil das ESFs, em que nem toda a população está vinculada. 


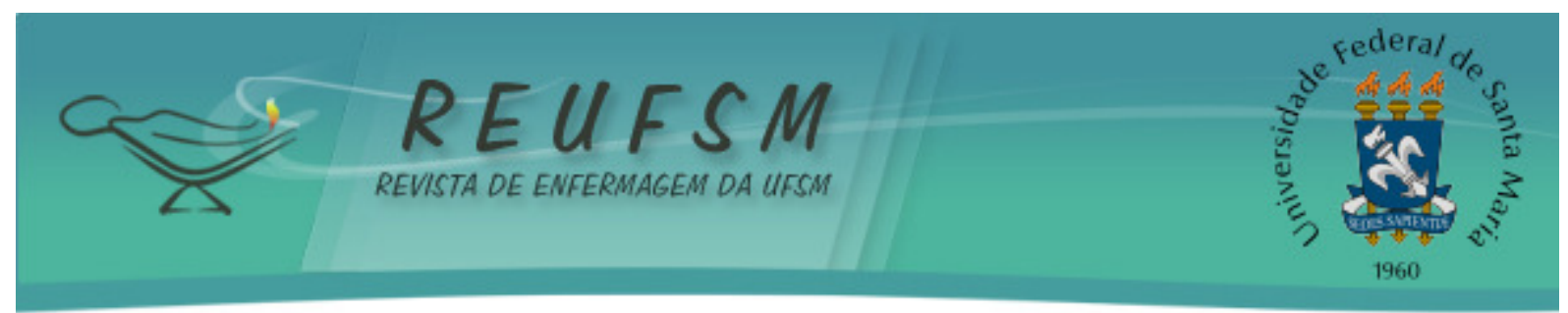

Embora apenas um dos sujeitos mencione a questão do tratamento farmacológico (E2), os cuidados de enfermagem que podem favorecer para melhorar a qualidade de vida não são citados pelos entrevistados. Pois além da sintomatologia específica, deve-se atentar, também, para as alterações de olfato e de sono, hipotensão postural, constipação, depressão, ansiedade, sintomas psicóticos, demência e outros prejuízos no campo da cognição. ${ }^{15}$ Para além da terapia medicamentosa estes pacientes precisam receber atenção especial da enfermagem e da equipe multiprofissional para que saibam como intervir frente às modificações que os acompanharão no convívio com a doença de Parkinson.

Os cuidados de enfermagem incluem orientações quanto à alimentação, uso de espessantes e alimentos que minimizem riscos de aspiração para o paciente. Outro fator importante a ser abordado pelos profissionais da equipe de enfermagem refere-se ao isolamento social, derivado tanto pela presença de sintomas motores quanto por outros fatores como dificuldade de locomoção, sialorréia e dificuldade de fala. A enfermagem e a equipe como um todo devem, ainda, estar atentos para problemas como constipação, que pode ser minimizada com o aumento da ingesta de fibras e água e com a prática regular de exercícios físicos. ${ }^{15}$

Além da atuação da enfermagem, o paciente com DP precisa ser acompanhado por outros profissionais como: fonoaudiólogo, fisioterapeuta, nutricionista, urologista e psicólogo, além é claro do neurologista e do clínico geral. ${ }^{16} \mathrm{~A}$ enfermagem, especificamente, dá suporte assistencial, principalmente no que se refere as alterações advindas do processo de envelhecimento, de quadros somáticos, a condição da DP e acompanhamento dos efeitos resultantes do uso de fármacos. 0 desconhecimento desses fatores e dessas estratégias de cuidado acaba gerando uma lacuna na assistência e a ausência de ações efetivas que poderiam evitar problemas futuros para o paciente com DP e sua família. ${ }^{9,15}$

\section{Cuidados direcionados aos familiares de usuários com doença de Parkinson}

Mesmo não evidenciando ações específicas direcionadas á atenção aos usuários com DP, esta categoria, traz algumas ações importantes que potencializam os familiares para os cuidados direcionados aos usuários com DP. A participação da família durante o tratamento e evolução da DP de um familiar, é visto como fundamental, tanto pelo profissional de saúde quanto pelo próprio usuário. ${ }^{9}$

$E$ É é...acho que de repente se tivesse um, dois, acredito que numa área de estratégia não seriam muitos... mas daria pra gente estar pensando em nível municipal, eu sei que em outros municípios tem ... grupos de apoio que os familiares vão estudar melhor pra ajudar a manter a qualidade de vida dos pacientes. (E1)

A identificação de usuários com DP permite que a organização da atenção possa ser articulada entre trabalhadores da saúde e familiares. Assim, a constante troca de informações possibilita aos cuidadores, sejam eles familiares ou profissionais, implementar ações que visem melhorar a qualidade de vida destes usuários dos serviços de saúde.

Investigação ${ }^{5}$ realizada sobre a vivência corporal e os efeitos na capacidade funcional de usuários com doença de Parkinson evidenciou que a participação em grupos favorece a união, a solidariedade e a socialização, uma vez que propicia espaço de troca e ajuda mútua. 0 estudo mostrou, ainda, que raramente os parkinsonianos têm oportunidades de participar de atividades grupais. Para isso, deve-se estimular a integração dos mesmos, utilizando grupos de convivência como uma tecnologia estratégica para promover o bem-estar integral dos participantes. ${ }^{5}$ 


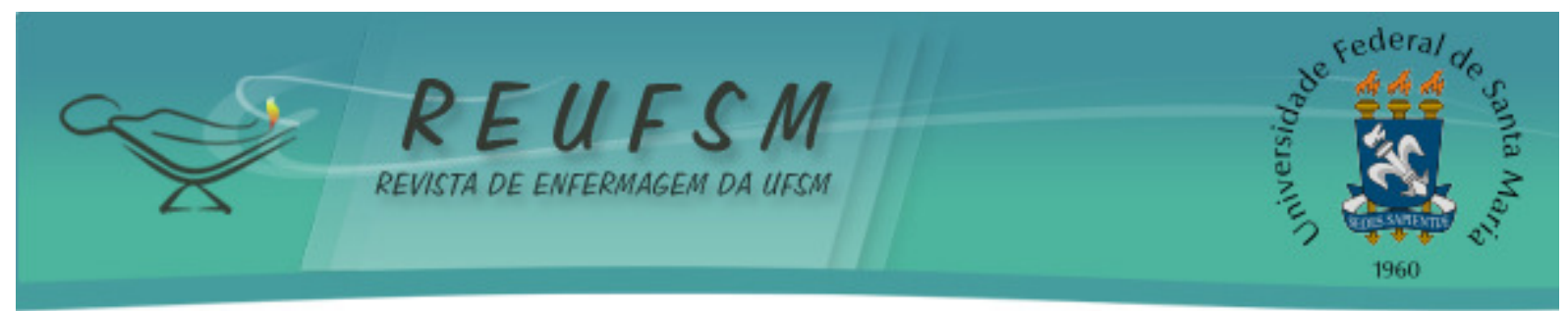

Estudo $^{16}$ realizado sobre a percepção de idosos de uma unidade de saúde da família acerca da sua qualidade de vida demonstrou que os aspectos relativos à afetividade e cuidados dos familiares são essenciais para os idosos, particularmente, para aqueles que estão vivenciando condições de cronicidade das doenças e que apresentam limitações para realizar as atividades de vida diária.

As ações educativas aos familiares de pacientes com doença de Parkinson são importantes para que esses possam entender os sinais e sintomas, os cuidados e a terapêutica medicamentosa. Ter mais informações a respeito da doença é primordial para fazer a adequações no cuidado de acordo com as necessidades de cada usuário.

Mas eu acho que a informação seria importantíssima para você poder lidar com essa situação e com o paciente. Acho que é importante informar os familiares dos sintomas e do tratamento também. (E5)

Fazer um grupo separado - dos familiares - e num outro momento fazer os dois juntos, com o paciente e com o familiar. (E7)

Os entrevistados citaram orientações que acreditam ser necessário, indo ao encontro do que é preconizado, quanto ao papel da família. Dentre elas está a interatividade com essa, acompanhada de comprometimento, envolvimento e diálogo, o que facilita a qualidade de vida do paciente e dela própria. Desse modo, a família precisa ser vista como uma consorte no tratamento, ser compreendida, valorizada e instrumentalizada pela equipe de saúde. Surgirão muitas dúvidas a respeito do progresso da doença e suas repercussões na vida diária e os profissionais precisam estar sensibilizados para isso, buscando e ofertando alternativas. ${ }^{17}$

Os grupos de convivência, citados direta ou indiretamente pelos entrevistados, constituem-se em uma importante rede de apoio que mobiliza os participantes em busca de autonomia, autoestima, fazendo com que os familiares socializem, reconheçam valores e assimilem vivências comuns, se constituindo em um espaço de troca de saberes e experiências.

\section{O usuário com doença de Parkinson na Atenção Básica}

Diversas estratégias de atenção devem ser articuladas nos serviços de saúde, uma vez que essas ações embasam e qualificam o cuidado de enfermagem. Os dados da pesquisa mostram que existem múltiplos desafios aos enfermeiros quanto à implementação de propostas e programas que o Ministério da Saúde propõe para esse grupo de usuários. Essas se evidenciam nas falas abaixo:

Nesse caso, para os doentes, para os pacientes de Parkinson não sei se tem algum protocolo específico, mas para todas as outras áreas a gente sempre segue os protocolos do Ministério da Saúde. (E1)

Então, não temos políticas nessa área também. A princípio tem mais geral, mas especificamente pra Parkinson não. (E3)

Por não ter o paciente eu acho que a gente não se aprofunda muito na questão. (E4) 


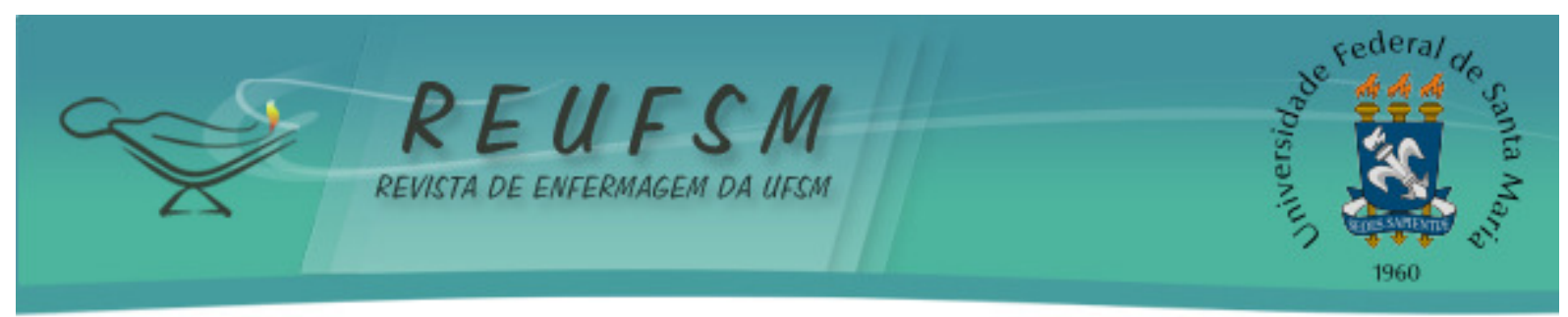

A gente não tem os casos e a gente não tem nenhuma política estabelecida... Não tenho nada de rotina preconizada para esse tipo de tratamento. (E5)

No ano de 2012, a Organização Pan-Americana de Saúde (OPAS) e a Organização Mundial de Saúde $(\mathrm{OMS})^{18}$ financiaram uma publicação direcionada ao enfrentamento das condições crônicas no âmbito do Sistema único de Saúde. Tal publicação tem relação com a criação da Rede de Atenção as Doenças Crônicas pelo Ministério da Saúde, que vem ofertando já há algum tempo diretrizes que teoricamente devem guiar as equipes frente as mais diversas situações, dentre as quais a população idosa.

Embora estas ofertas sejam recentes ${ }^{6,18}$ elas precisam ser inseridas no cotidiano de todas as equipes de saúde da família do país. Conquanto, não tenha sido criada especificamente para doenças crônico-degenerativas, a maioria das orientações abrangem também as demandas dessas, podendo ser utilizadas tanto para população com DP, quanto para os demais usuários com outros agravos crônicos.

0 questionamento que emerge versa sobre os desafios por parte dos enfermeiros sobre o assunto, uma vez que a Portaria $n^{\circ} 228 / 10$ do Ministério da Saúde propõe o "Protocolo Clinico e Diretrizes Terapêuticas para Doença de Parkinson" que abrange todo o território nacional, estabelecendo para isso, diretrizes de diagnóstico, tratamento, dispensação e controle de medicamentos, acompanhamento e registro dos pacientes, no âmbito estadual e municipal regulando o acesso assistencial e organizando a rede de referência para essa população. O mesmo documento traz, ainda, um termo de esclarecimento que deve ser assinado pelo paciente ou seu responsável legal para que haja dispensação dos medicamentos específicos para pacientes com DP. ${ }^{6}$

O enfrentamento das condições crônicas, quando se fala de saúde coletiva, demanda ações que ultrapassam o âmbito da gestão ou dos serviços de forma isolada. Pontua-se que um dos desafios, neste contexto, é o de desconstruir o modelo de atenção às condições e eventos agudos, empoderando o sujeito para que ele saiba prevenir, entender e conviver com o quadro crônico que se apresenta, além de citar a prática baseada em evidências e as parcerias com a comunidade como importantes ferramentas de suporte a atenção dessa população. ${ }^{17}$

Esses movimentos e articulações são dinâmicos, necessários e constantes, pois a estratificação destes implicaria diretamente em um cuidado não condizente e insuficiente às necessidades da população. Surgem também, a partir destas reflexões, aquelas inerentes à própria profissão da enfermagem quanto ao seu protagonismo na atenção as condições crônicas de saúde das pessoas e populações.

As questões que envolvem cuidados de enfermagem precisam ir além de tarefas genuinamente técnicas. Para tanto, faz-se necessária a compreensão da totalidade do ser que está sendo cuidado com suas limitações, necessidades e particularidades. Urge, ainda, uma reflexão voltada aos modos de relacionamento com o outro, pois o cuidado é a essência do trabalho da enfermagem. ${ }^{19}$ Esse movimento reflexivo tem por resultado a promoção de avaliações sobre modos de agir, alternativas para melhoria da assistência e o exercício de considerações acerca da complexa individualidade dos sujeitos. ${ }^{19}$

\section{CONSIDERAÇÕES FINAIS}

Este estudo buscou discutir acerca dos cuidados de enfermagem aos usuários com Doença de Parkinson nas Estratégias de Saúde da Família. Os resultados evidenciam que não há registro de usuários com essa patologia na área de abrangência deste estudo. Diante disso, verifica-se que o cuidado de enfermagem a estes indivíduos fica comprometido, uma vez que há uma série de ações que devem ser direcionadas 


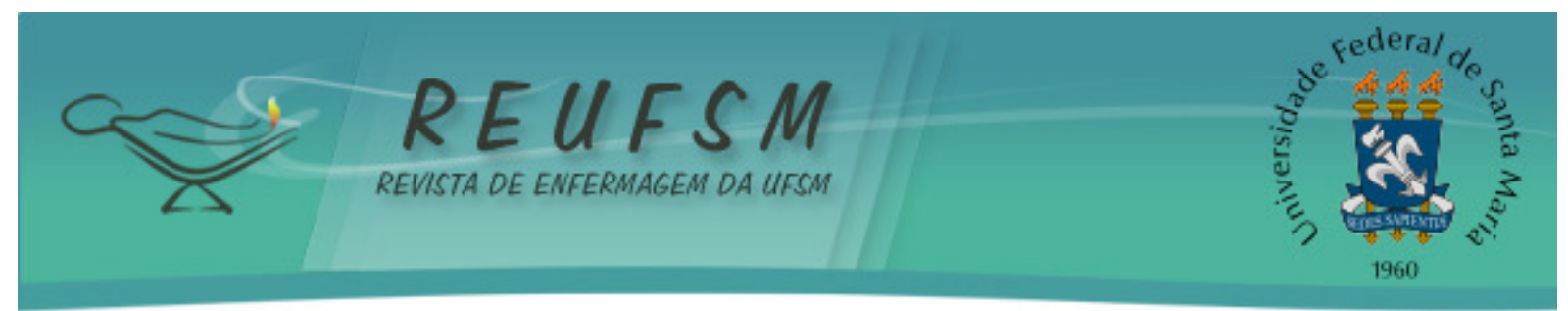

especificamente para os usuários da atenção básica que tenham a DP. Se não há registro, entende-se que, também, pode não ter diagnóstico e, portanto, haver pacientes que não estão sendo tratados e cuidados da forma como deveriam ser.

Outro dado mostra que, mesmo não evidenciando cuidados específicos direcionados aos usuários com DP, os enfermeiros mencionam que a participação da família durante o tratamento e evolução da DP de um familiar é relevante. Para tanto, deve-se contemplar e incluir os integrantes da família no planejamento dos cuidados de enfermagem aos usuários que possuem a doença de Parkinson e que acessam a atenção básica de saúde.

Guardadas as limitações do estudo, considera-se necessário o desenvolvimento de estudos investigativos para buscar resultados objetivos que evidenciem as dimensões e a extensão das tecnologias cuidativas, incluindo as atividades grupais destinadas ao indivíduo com DP e sua família. Também, a realização de pesquisas que visem o desvelamento de comportamentos particulares de cuidado para um viver com qualidade e bem estar possível, enfrentando as adversidades da cronicidade imposta pela doença, tanto da família como da comunidade.

\section{REFERÊNCIAS}

1. Lima-Costa MF, Camarano AA. Demografia e epidemiologia do envelhecimento no Brasil. In: Moraes EN. Princípios básicos de geriatria e gerontologia. Belo Horizonte (MG): Coopmed; 2008. p. 01-19.

2. Ministério da Saúde (BR). Secretaria de Atenção à Saúde. Departamento de Atenção Básica. Envelhecimento e saúde da pessoa idosa. Brasília (DF): Ministério da Saúde; 2006. (Série A. Normas e Manuais Técnicos, Cadernos de Atenção Básica; 19).

3. Maia DP, Teixeira Júnior AL, Cunningham MCQS, Cardoso F, Goulart FRP, Salmela LFT, et al. Tremores no idoso: diagnóstico, tratamento e fisioterapia na doença de Parkinson. In: Moraes EN. Princípios básicos de geriatria e gerontologia. Belo Horizonte: Coopmed; 2008. p. 477-485.

4. Maia FM. Avaliação da geração de palavras, em indivíduos com doença de Parkinson, através de ressonância magnética funcional [tese]. São Paulo: Universidade de São Paulo, Faculdade de Medicina; 2009.

5. Gonçalves LHT, Benedetti TRB, Lopes MA, Vilela ABA, Santos CA. Vivência corporal para portadores de doença de Parkinson: efeitos na capacidade funcional. Geriatria \& Gerontologia. 2010;4(2):62-8.

6. Brasil. Ministério da Saúde. Portaria SAS/MS n² 228, de 10 de maio de 2010. Protocolo clínico e diretrizes terapêuticas - Doença de Parkinson (anexo)[Internet]. [acesso em 2013 out 2]. Disponível em: http://bvsms.saude.gov.br/bvs/saudelegis/sas/2010/ prt0228_10_05_2010.html

7. Santos ISC, Menezes MR, Souza AS. Elderly people's conceptions of living with parkinson's disease. Rev Enferm UERJ [Internet]. 2009 jan/mar [acesso em 2013 out 2];17(1):69-74. Disponível em: http://www.facenf.uerj.br/v17n1/v17n1a13.pdf.

8. Aguiar PMC, Severino P. Biomarcadores na doença de Parkinson: avaliação da expressão gênica no sangue periférico de usuários com e sem mutações nos genes PARK2 e PARK8. Einstein. 2010;8(3):291-7.

9. Gonçalves LHT, Alvarez AM, Arruda MC. Pacientes portadores da doença de Parkinson: significado de suas vivências. Acta Paul Enferm. 2007;20(1):62-8. 


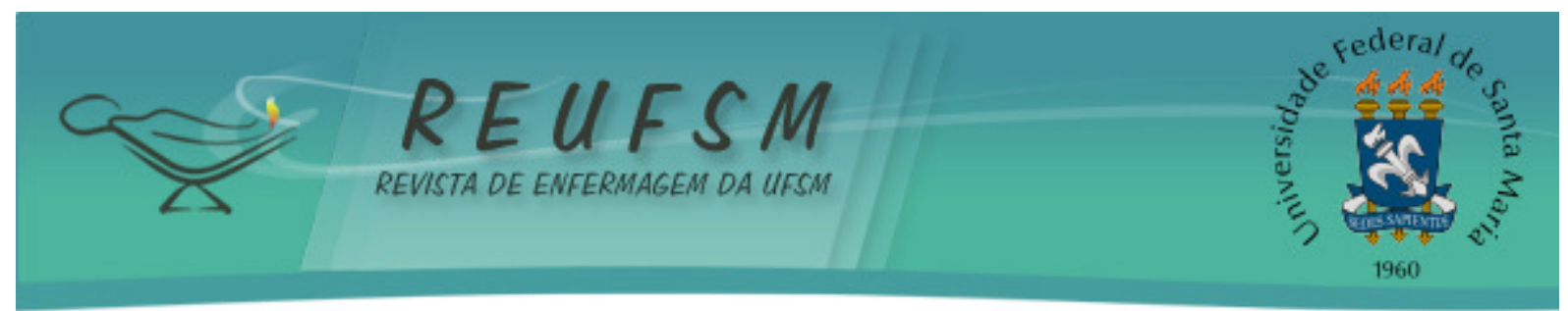

10. Minayo MCS. O desafio do conhecimento: pesquisa qualitativa em saúde. $2^{\mathrm{a}}$ ed. São Paulo: Hucitec-Abramo; 2007.

11. Barbosa MT, Caramelli P, Maia DP, Cunningham MC, Guerra HL, Lima-Costa MF, et al. Parkinsonism and Parkinson's disease in the elderly: a community based survey in Brazil (the Bambuí study). Mov Disord. 2006;21(6):800-8.

12. Turato ER. Tratado da metodologia da pesquisa clínico-qualitativa. Petrópolis (RJ): Vozes; 2003.

13. Bardin L. Análise de conteúdo. São Paulo: Edições 70; 2011.

14. Conselho Nacional de Saúde (BR). Resolução CNS n 196, de 10 de outubro de 1996. Diretrizes e normas regulamentadoras de pesquisas envolvendo seres humanos. Brasília (DF): Conselho Nacional de Saúde; 1996.

15. Rieder CRM. Manifestações não motoras da doença de Parkinson. In: Reis T. Doença de Parkinson: busca da qualidade de vida. Porto Alegre (RS): Imprensa Livre, 2012. p. 59-83.

16. Alves ERP, Dias MD, Costa AM, Silva ARS, Silva MM, Seabra RV. Qualidade de vida: percepção de idosos de uma unidade de saúde da família. Rev Enferm UFSM [Internet]. 2012 set/dez [acesso em 2013 jan 10];2(3):487-95. Disponível em: http://cascavel.ufsm.br/ revistas/ojs-2.2.2/index.php/reufsm/article/view/5240/pdf

17. Navarro-Peternella FM, Marcon SS. A convivência com a doença de Parkinson na perspectiva do parkinsoniano e seus familiares. Rev Gaúcha Enferm. 2010;31(3):415-22.

18. Mendes EV. O cuidado das condições crônicas na atenção primária à saúde: o imperativo da consolidação da estratégia da saúde da família. Brasília: Organização PanAmericana da Saúde; 2012.

19. Baggio MA, Callegaro GD, Erdmann AL. Relações de "não cuidado" de enfermagem em uma emergência: que cuidado é esse? Esc Anna Nery Rev Enferm. 2011 jan-mar;15(1):116-23.

Data de recebimento: 03/06/2013

Data de aceite: $13 / 12 / 2013$

Contato com autor responsável: Luiz Anildo Anacleto da Silva

Endereço postal: Av. Independência, $\mathrm{n}^{\circ}$ 3751, Bairro Vista Alegre, Palmeira das Missões, Rio Grande do Sul. CEP-98300-000

E-mail: luiz.anildo@yahoo.com.br 